\title{
Poster
}

\section{ROLE OF PERIODISATION AND TRAINING METHOD IN SPORTS}

Bharti Rathi, Gaganpreet Kaur, Vishaw Gaurav Department of Physical Education (T), GNDU, Amritsar, Punjab, India

\subsection{6/bjsm.2010.078725.168}

The concepts 'training' and sportsman's 'preparation' in the main coincide, but are not identical. Periodisation and training are the main components and the basic form of preparing the athlete. In other words, it is systematically planned preparation with the help of the exercise methods which realises the main factors of influencing athletes' progress. The content of training includes all the basic types of preparation of the sportsman - physical, technical, tactical and psychological. Systematic training improves the athlete's fitness level. It is the basis of his preparedness for sporting achievements. At the same time, training has an impressive effect on the athlete's physical and spiritual development and his acquisition of vital knowledge and skills. Today even a highly talented sportsman is not in a position to win a medal unless he possesses a certain minimum of the above mentioned factors. It has also become increasingly clear that these factors cannot be developed to the desired level in 1 or 2 years. It is necessary for a person to develop adequate level of physical fitness early in life and then continuously maintain it through regular participation in a well designed activity programme to promote his total physical well being flexibility along with strength, speed and endurance is one of the very basic components of physical fitness (Uppal 1983). 